\title{
Small for Gestational Age with Failure of Catch-Up Growth
}

National Cancer Institute

\section{Source}

National Cancer Institute. Small for Gestational Age with Failure of Catch-Up Growth. NCI

Thesaurus. Code C118702.

A condition in which a child who was born small for gestational age, fails to achieve a linear growth rate sufficient to restore height to within the normal range for the reference population. 